\title{
Fabrication of Mesoporous Metal Chalcogenide Nanoflake Silica Thin Films and Spongy Mesoporous CdS and CdSe
}

\author{
Yurdanur Türker, Cüneyt Karakaya, and Ömer Dag*[a]
}

\begin{abstract}
Mesoporous silica metal oxide $(\mathrm{ZnO}$ and $\mathrm{CdO})$ thin films have been used as metal ion precursors to produce the first examples of mesoporous silica metal sulfide (meso$\mathrm{SiO}_{2} @ \mathrm{ZnS}$, meso-SiO$\left.{ }_{2} @ \mathrm{CdS}\right)$ or silica metal selenide (meso- $\mathrm{SiO}_{2} @ \mathrm{ZnSe}$, meso-SiO$\left.{ }_{2} @ \mathrm{CdSe}\right)$ thin films, in which the pore walls are made up of silica and metal sulfide or metal selenide nanoflakes, respectively. A gentle chemical etching with a dilute HF solution of the meso-SiO $@$ @dS (or meso$\mathrm{SiO}_{2} @ \mathrm{CdSe}$ ) produces mesoporous cadmium sulfide (meso-CdS) (or cad-
\end{abstract}

mium selenide, meso-CdSe). Surface modified meso-CdS displays bright blue photoluminescence upon excitation with a UV light. The mesoporous silica metal oxides are formed as metal oxide nanoislands over the silica walls through a self-assembly process of a mixture of metal nitrate salt-two surfactants-silica source followed by calcination step. The reactions, between the

Keywords: mesoporous materials • metal selenides $\cdot$ metal sulfides . nanomaterials $\cdot$ thin films

\begin{abstract}
$\mathrm{H}_{2} \mathrm{~S}$ (or $\mathrm{H}_{2} \mathrm{Se}$ ) gas and solid precursors, have been carried out at room temperature and monitored using spectroscopy and microscopy techniques. It has been found that these reactions are: 1) taking place through the diffusion of sulfur or selenium species from the top metal oxide layer to the silica metal oxide interface and 2) slow and can be stopped at any stage to obtain mesoporous silica metal oxide metal sulfide or silica metal oxide metal selenide intermediate thin films.
\end{abstract}

\section{Introduction}

Chemistry at the nanoscale and/or mesoscale offers many new synthetic approaches for designing new materials with unique structures and functions. ${ }^{[1]}$ Designing two or more materials in one, such as insulator-semiconductor, semiconductor-semiconductor, metal-insulator, and metal-semiconductor couples with an atomic precision is still a challenge in synthetic chemistry. In the last two decades, chemists have focused on solution based methods for the synthesis of multicomponent materials such as core-shell type structures, layer by layer assembly, and monolayer coatings. ${ }^{[2-6]}$ There have also been many attempts to link nanoparticles to each other using organic linkers ${ }^{[7,8]}$ or porous materials as hosts to grow second or third component in the channels. ${ }^{[9-21]}$ However, all these methods require a second or third step and create in-homogeneities in size and shape distribution of the nanoparticles. The mesoporous materials in the form of thin films, monoliths, or powders with many different shapes have been known for the last 20 years; however uniform (size, shape, and composition) surface coating has always been a challenge. The mesoporous silica specifically

[a] Y. Türker, C. Karakaya, Prof. Ö. Dag

Department of Chemistry, Bilkent University

06800 Ankara (Turkey)

Fax: (+90)312-266 4068

E-mail: dag@fen.bilkent.edu.tr

Supporting information for this article is available on the WWW under http://dx.doi.org/10.1002/chem.201102643.
MCM-41 and SBA-15-has been widely employed as a hard template to obtain transition-metal oxides, metals, and metal chalcogenide nanoparticles. ${ }^{[9-21]}$ The major problem has always been the limited amount of metal ions that can be incorporated into the channels of mesoporous silica and their in-homogeneous distribution (as a result the oxides, metals, and/or chalcogenides in the channels are also randomly sized and distributed) $\cdot{ }^{[9-13]}$ There is definitely a demand for new synthetic methods to produce mesoporous metal oxides, metal sulfides, and metal selenides with or without silica (or another oxide, such as titania) for optoelectronic and solar energy applications. It is also important to note that the synthesis of pure and stable mesoporous metal sulfides and metal selenides has always been a challenge over the years. ${ }^{[18-26]}$ There have been many attempts, using soft and hard templating methods, to overcome the stability problems. ${ }^{[18-26]}$ Soft templating (lyotropic liquid crystalline templating, LLCT) produced either extremely small mesostructured metal sulfide powders ${ }^{[22-25]}$ or even thin films ${ }^{[26]}$ that are unstable to surfactant removal. ${ }^{[22-26]}$ Hard or a combination of hard/soft templating methods have also been investigated by many groups, but these methods always produced nanoparticles or nanowires in the channels of the mesoporous host. ${ }^{[9-21]}$ It is worth to mention that there are also a few studies on metal sulfide aerogels with a relatively high surface area, however with a much thicker walls. ${ }^{[27-30]}$ Recently, we have discovered that some transition-metal salts can be kept in their liquid phase in the hydrophilic domains of LLC mesophase of a salt-surfactant system. ${ }^{[31]}$ The same concept has already been used to 
design the first homogenously metal oxide coated mesoporous silica thin films in which the metal oxide layer can be more than 53 mole percent (about $70 \% \mathrm{w} / \mathrm{w}$ ) and as thin as 1.3 to $1.7 \mathrm{~nm} \cdot{ }^{[32]}$ In this self-assembly process, the salt species act as solvents, like water, in the media to organize the surfactant molecules into LLC mesophases ${ }^{[31]}$ and metastable salt-surfactant-silica mesostructured thin films. ${ }^{[32]}$ The silica walls can be fully or partially coated with crystalline ultra thin metal oxide layers that can be converted into metal sulfide (or metal selenide) coated silica. The silica walls can be etched out to form stable mesoporous metal sulfide (or metal selenide) thin films. ${ }^{[32]}$

Herein, the synthetic pathway of mesoporous metal sulfide (or metal selenide) silica (MMSS), metal oxide metal sulfide (or selenide) silica (MOMSS) and pure metal sulfide (and metal selenide) (MMS) has been investigated. It has been proven that the oxide over layers can be partially or fully reacted with $\mathrm{H}_{2} \mathrm{~S}$ or $\mathrm{H}_{2} \mathrm{Se}$ at RT to convert them into metal sulfides or metal selenides. Both reactions, $\mathrm{H}_{2} \mathrm{~S}$ and $\mathrm{H}_{2} \mathrm{Se}$, can be controlled, as a result the metal oxide and metal sulfide (or metal selenide) thickness in the MOMSS films, using exposure time and monitored using FTIR, UV/ Vis, and EDS spectroscopic techniques. Pure MMS thin films were also obtained by carefully etching the silica from the MMSS thin films. The film samples, at each stage, were characterized using TEM, SEM, EDS, UV/Vis, FTIR, Raman, and XRD techniques.

\section{Results and Discussion}

Mesoporous silica metal sulfide/selenide and cadmium sulfide/selenide thin films: The $400-600 \mathrm{~nm}$ thin films of the mesoporous silica zinc oxide and silica cadmium oxide have been prepared using the procedure established in our earlier work. ${ }^{[32]}$ The films were obtained by first spin coating a homogenized clear solution of $\left[\mathrm{M}\left(\mathrm{H}_{2} \mathrm{O}\right)_{x}\right]\left(\mathrm{NO}_{3}\right)_{2}-\mathrm{H}_{2} \mathrm{O}-\mathrm{CTAB}-$ $\mathrm{HNO}_{3}-\mathrm{C}_{12} \mathrm{EO}_{10}$-TMOS ( $\mathrm{M}$ is $\mathrm{Zn}^{\mathrm{II}}$ or $\mathrm{Cd}^{\mathrm{II}}$ and $x$ is 6 for $\mathrm{Zn}^{\mathrm{II}}$ and 4 for $\mathrm{Cd}^{\mathrm{II}}$ salts) mixture and then, immediately, calcined starting from 55 and $65^{\circ} \mathrm{C}$ to $450^{\circ} \mathrm{C}$, respectively. ${ }^{[32]}$ This process gives mesoporous silica metal oxide thin films (denoted as meso- $\mathrm{SiO}_{2}-\mathrm{MO}-n, \mathrm{M}$ is $\mathrm{Zn}^{\mathrm{II}}$ or $\mathrm{Cd}^{\mathrm{II}}$ and $n$ is the $\mathrm{M}$ / $\mathrm{Si}$ mole ratio), where the metal oxide forms nanoislands with a thickness of around $1.6 \mathrm{~nm}$ over the silica walls (see ref. [32] for details).

The meso-SiO $2-\mathrm{MO}-n$ thin films were exposed to a $\mathrm{H}_{2} \mathrm{~S}$ or $\mathrm{H}_{2} \mathrm{Se}$ atmosphere to obtain mesoporous silica metal sulfide and silica metal selenide thin films. The reactions were carried out under a 300 Torr $\mathrm{H}_{2} \mathrm{~S}$ atmosphere at RT to prepare meso-SiO ${ }_{2} @ \mathrm{ZnS}-n$ and meso-SiO${ }_{2} @ \mathrm{CdS}-n$ (where $n$ is 0.29 , $0.57,0.86$, and 1.14) and 300 Torr mixture of $5 \% \mathrm{H}_{2} \mathrm{Se}$ in pure $\mathrm{N}_{2}$ to prepare meso-SiO$@ @ \mathrm{ZnSe}-n$ and meso$\mathrm{SiO}_{2} @ \mathrm{CdSe}-n$ samples. In a total of 16 samples, 4 samples from each set, were prepared with increasing metal ion content and were characterized using spectroscopy, microscopy, and diffraction techniques. Figure 1 shows a typical SEM image of meso-SiO${ }_{2} @ \mathrm{CdS}-0.86$ after $\mathrm{H}_{2} \mathrm{~S}$ reaction. Disor-

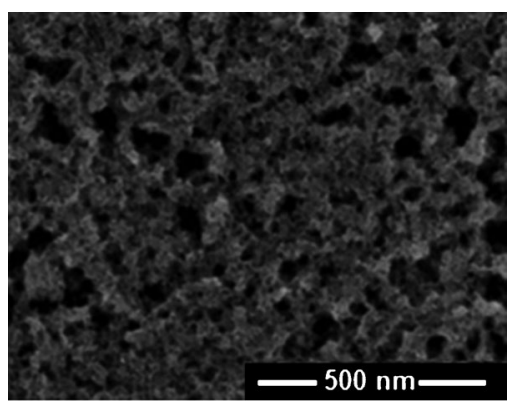

Figure 1. High-resolution SEM images of the meso-SiO $\mathrm{S}_{2} \mathrm{CdS}-0.86$.

dered/non-uniform sponge-like pores, ranging from 3 to $20 \mathrm{~nm}$ (meso-pores) and 50-100 nm (macro-pores) are visible in the images. The images of all other samples display similar surface morphology and texture. The complete conversion of the metal oxides to metal sulfides or to metal selenides was ensured using the EDS and FTIR technique. The EDS data show a linear increase of the $\mathrm{Zn} / \mathrm{Si}$ and $\mathrm{Cd} / \mathrm{Si}$ intensity ratios with an increasing $n$ from 0.29 to 1.14 , showing the homogeneity in the meso- $\mathrm{SiO}_{2}-\mathrm{MO}-n$, meso$\mathrm{SiO}_{2} @ \mathrm{MS}-n$ and meso-SiO${ }_{2} @ \mathrm{MSe}-n$ thin films. The EDS S/ $\mathrm{Zn}, \mathrm{Se} / \mathrm{Zn}, \mathrm{S} / \mathrm{Cd}$, and $\mathrm{Se} / \mathrm{Cd}$ intensity ratio increase and reaches to bulk $\mathrm{ZnS}, \mathrm{ZnSe}, \mathrm{CdS}$, and $\mathrm{CdSe}$ values during the $\mathrm{H}_{2} \mathrm{~S}$ or $\mathrm{H}_{2} \mathrm{Se}$ reactions, respectively, showing the complete conversion of the metal oxides to metal sulfide or metal selenide.

The FT-IR spectra of the meso-SiO play peaks at around $850-1000 \mathrm{~cm}^{-1}$ and $450-550 \mathrm{~cm}^{-1}$ ranges, due to the $\tilde{v} \mathrm{Si}-\mathrm{O}$ stretching mode of the surface silicon-oxygen bonds, attached to a zinc or cadmium (Si-O-Zn (or Cd)) and silica deformation modes and/or $\mathrm{ZnO}$ or $\mathrm{CdO}$ stretching modes, respectively, see Figure $2 a$ and $b .{ }^{[32]}$ Upon complete conversion of the metal oxides to the metal sulfides (or metal selenides), the peak at $926 \mathrm{~cm}^{-1}$, of the meso- $\mathrm{SiO}_{2}-\mathrm{ZnO}-n$ sample(s) shifted to $1067 \mathrm{~cm}^{-1}$ and the peak at $536 \mathrm{~cm}^{-1}$ shifted to $456 \mathrm{~cm}^{-1}$, which are corresponding to pure silica stretching and breathing modes, respectively, see Figure 2. The zinc oxide domains are chemically bonded to the silica surface with $\mathrm{O}_{3} \mathrm{Si}-\mathrm{O}-\mathrm{ZnO}_{3}$ interface that can be identified by the peaks at 926 and $536 \mathrm{~cm}^{-1}$ in the meso- $\mathrm{SiO}_{2}-\mathrm{ZnO}-n$ samples. ${ }^{[32]}$ The meso-SiO ${ }_{2}-\mathrm{CdO}-n$ samples also display a peak and a shoulder at 914 and $864 \mathrm{~cm}^{-1}$, respectively, due to the $\mathrm{O}_{3} \mathrm{Si}-\mathrm{O}-\mathrm{Cd}(\mathrm{O})_{5}$ interface. The crystalline $\mathrm{ZnO}$ and $\mathrm{CdO}$ domains, on the silica surface, grow as nanoislands with a wurtzite (four coordinated) and $\mathrm{NaCl}$ (six coordinated) structures, respectively. ${ }^{[32]}$ In both meso$\mathrm{SiO}_{2}-\mathrm{ZnO}-n$ and meso-SiO$-\mathrm{CdO}-n$ samples, the peaks due to $\mathrm{Si}-\mathrm{O}-\mathrm{M}$ bonds disappear and the peaks due to the pure silica appear upon completion of the $\mathrm{H}_{2} \mathrm{~S}$ or $\mathrm{H}_{2} \mathrm{Se}$ reactions, see Figure 2. The complete reactions break the metal oxygen, $\mathrm{Si}-\mathbf{O}-\mathbf{M}\left(\mathrm{M}\right.$ is $\mathrm{Zn}^{\mathrm{II}}$ or $\left.\mathrm{Cd}^{\mathrm{II}}\right)$, bond at the silica metal oxide interface, therefore we represented the metal sulfide and metal selenide samples as meso-SiO $2 @ \mathrm{MS}-n$ and meso$\mathrm{SiO}_{2} @ \mathrm{MSe}-n$, respectively. The Raman spectra of the meso$\mathrm{SiO}_{2} @ \mathrm{CdS}-n, m e s o-\mathrm{SiO}_{2} @ \mathrm{ZnSe}-n$, and meso-SiO ${ }_{2} @ \mathrm{CdSe}-n$ 

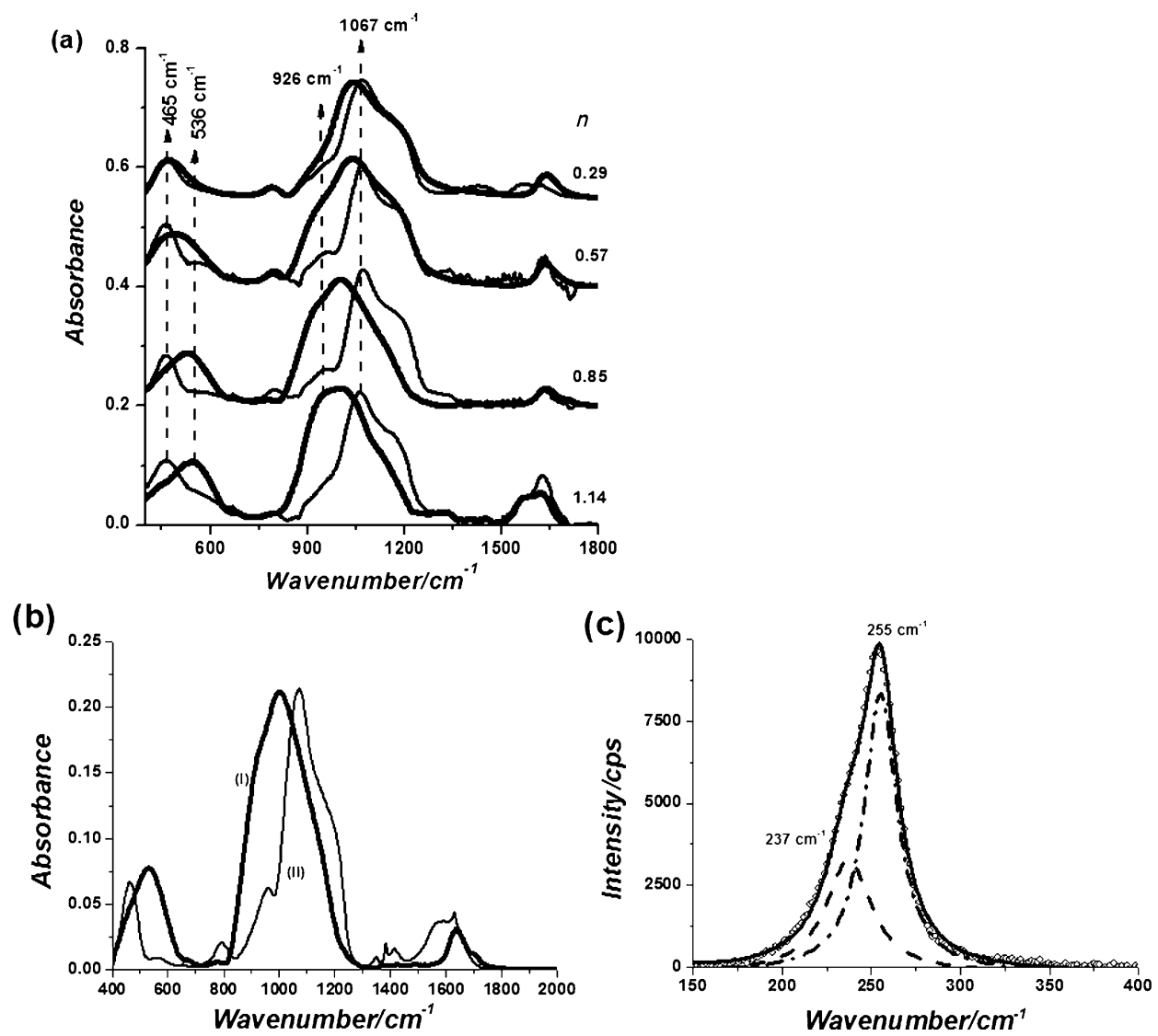

Figure 2. FTIR spectra of a) meso-SiO $-\mathrm{ZnO}-n$ ( $n$ is given in the spectra) thin films before and after complete $\mathrm{H}_{2} \mathrm{~S}$ reactions, $n$ is shown on each spectrum and b) before (I) and after (II) $\mathrm{H}_{2} \mathrm{Se}$ reaction of $m e s o-\mathrm{SiO}_{2}-\mathrm{ZnO}_{-}$ 0.86. c) The Raman spectra of meso-SiO $\mathrm{O}_{2} @ \mathrm{ZnSe}-0.86$ thin films.

films display intense Raman peaks due to longitudinal optical (LO) modes at 298, 250, and $205 \mathrm{~cm}^{-1}$, respectively, with shoulders on their low energy side due to surface modes, ${ }^{[33]}$ see Figure 2c. Notice that the Raman peaks of the CdS, $\mathrm{ZnSe}$, and CdSe crystallites are quite broad compared to the bulk silicon peak at $520 \mathrm{~cm}^{-1}$ and redshifted compared to bulk counterparts due to the phonon confinement effect. ${ }^{[34]}$ For instance, there is an about $6.2 \mathrm{~cm}^{-1}$ redshift in the meso$\mathrm{SiO}_{2}-\mathrm{CdSe}$ from its bulk CdSe. The shifts and the surface modes, observed as a shoulder on the low energy side of the LO modes, indicate the formation of nanostructured CdSe domains. $^{[34]}$

To further characterize the optical properties of the films, the UV/Vis absorption spectra were also recorded using thin films, prepared over quartz or glass slides of all 4 sets of samples upon $\mathrm{H}_{2} \mathrm{~S}$ or $\mathrm{H}_{2} \mathrm{Se}$ reactions, Figure 3. The band-gap energies of the samples were evaluated by extrapolating the absorption edge to zero on the energy axis of the square of the absorbance time energy $\left(A^{2 *} h v^{2}\right.$, direct-gap relationship) versus energy plots, see insets in Figure $3 \mathrm{a}, \mathrm{b}, \mathrm{c}$, and $\mathrm{d}$. The band gaps of the films were determined to be between 2.66 and $2.78 \mathrm{eV}$ in the meso-SiO${ }_{2} @ \mathrm{CdS}-n, 2.02$ and $2.45 \mathrm{eV}$ in the meso-SiO ${ }_{2} @ \mathrm{CdSe}-n, 3.90$ and $4.07 \mathrm{eV}$ in the meso$\mathrm{SiO}_{2} @ \mathrm{ZnS}-n$, and 2.90 and $3.43 \mathrm{eV}$ in the meso-SiO $\mathrm{O}_{2} @ \mathrm{ZnSe}-$ $n$, respectively. The band gaps in all samples are blueshifted from their bulk counterparts due to quantum size effect (bulk values are 2.42, 1.74, 3.68, and $2.70 \mathrm{eV}$, respectively). ${ }^{[35]}$

Note also that there is a gradual redshift with an increasing $n$ in the meso-SiO$@ @ M S-n$ (or meso- $\left.\mathrm{SiO}_{2} @ \mathrm{MSe}-n\right)$, indicating a gradual increase in the thickness of the metal sulfide or metal selenide domains. The thickness of the metal sulfide and metal selenide domains were calculated using the bandgap values and effective mass model (EMM) developed by Brus. ${ }^{[36]}$ By using the density difference between the cadmium oxide and cadmium sulfide (or cadmium selenide) and assuming the growth of $\mathrm{CdO}$ nanoislands and their conversion to $\mathrm{CdS}$ or CdSe are lateral, one can estimate that the thickness of the $\mathrm{CdS}$ layers will change from 2.5 to $3.0 \mathrm{~nm}$ and the CdSe layer will change from 2.8 to $3.2 \mathrm{~nm}$ with an increasing $n$ from 0.29 to 1.14 in the meso-SiO $2 @ \mathrm{CdS}-n$ and meso- $\mathrm{SiO}_{2} @ \mathrm{CdSe}-n$, respectively. The analysis of the UV/Vis data (and also using the metal oxide data ${ }^{[32]}$ ) also show that the $1.3-1.7 \mathrm{~nm}$ thick metal oxide nanoislands can be converted into $2.5-3.2 \mathrm{~nm}$ thick metal sulfide or metal selenide nanoflakes upon complete reaction with $\mathrm{H}_{2} \mathrm{~S}$ or $\mathrm{H}_{2} \mathrm{Se}$, respectively. The predicted (from density change) and determined (using UV/Vis absorption data) thickness are consistent with each other and proves our lateral growth assumption.

The films were further analyzed using $\mathrm{N}_{2}$ sorption data, collected from two samples, meso-SiO $\mathrm{S}_{2} \mathrm{CdS}-0.86$ and meso$\mathrm{SiO}_{2} @ \mathrm{ZnS}-0.86$ using about 20-30 glass slides of each of the samples. Figure $4 \mathrm{a}$ and $4 \mathrm{~b}$ show the $\mathrm{N}_{2}$ sorption isotherms of a set of meso-SiO ${ }_{2}-\mathrm{CdO}-0.86$, meso- $\mathrm{SiO}_{2}-(\mathrm{CdO}-\mathrm{CdS})-0.86$ (partially reacted), meso- $\mathrm{SiO}_{2} @ \mathrm{CdS}-0.86$ (fully reacted) and meso-SiO $-\mathrm{ZnO}-0.86$, meso-SiO$-(\mathrm{ZnO}-\mathrm{ZnS})-0.86$ (partially reacted), and meso-SiO${ }_{2} @ \mathrm{ZnS}-0.86$ (fully reacted) samples. Clearly the $\mathrm{N}_{2}$ sorption data show type IV isotherms with a hysteresis loops, characteristic for the mesoporous materials. The BET surface area and the Barrett-Joyner-Halenda $(\mathrm{BJH})$ pore volume of the meso- $\mathrm{SiO}_{2}-\mathrm{CdO}-0.86$ increase, upon complete reaction with the $\mathrm{H}_{2} \mathrm{~S}$ gas, from 55 to $90 \mathrm{~m}^{2} \mathrm{~g}^{-1}$ and from 0.16 to $0.30 \mathrm{~cm}^{3} \mathrm{~g}^{-1}$, respectively.

The t-plots of the adsorption isotherms of the samples before the $\mathrm{H}_{2} \mathrm{~S}$ reaction show slight negative deviation in the 4-6 $\AA$ range, indicating the presence of some micropor- 

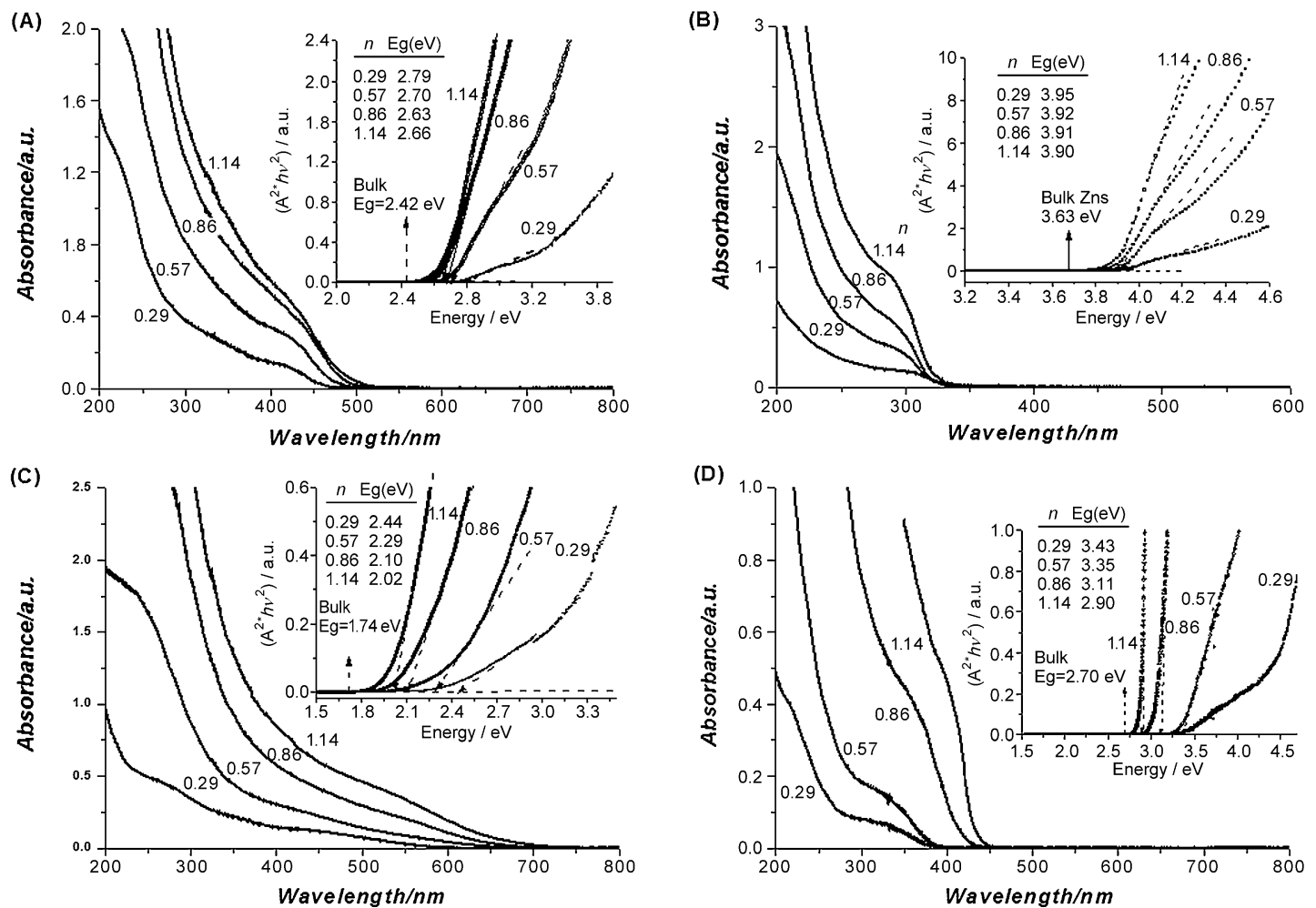

Figure 3. UV/Vis absorption spectra with insets of the plots of the direct band-gap relation $\left(\left(A^{*} h v\right)^{2}\right.$ versus $\left.h v\right)$ of the $m e s o$-SiO ${ }_{2} @ \mathrm{MS}-n($ or MSe- $n)$ where $n$ is shown on the plot, MS is a) CdS and b) ZnS, and MSe is c) CdSe and d) ZnSe.

(a)

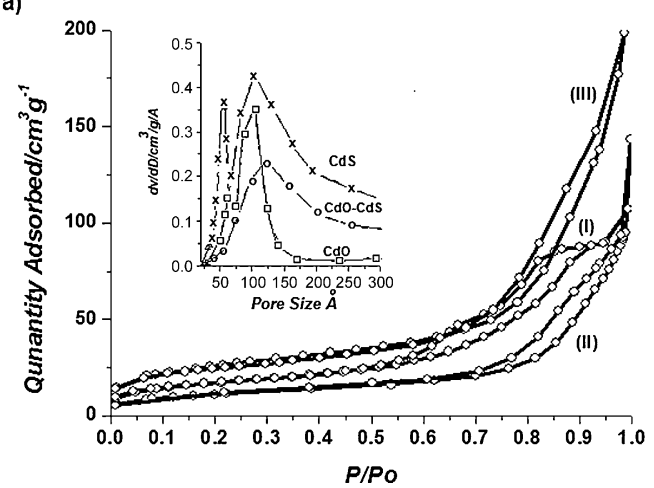

(b)

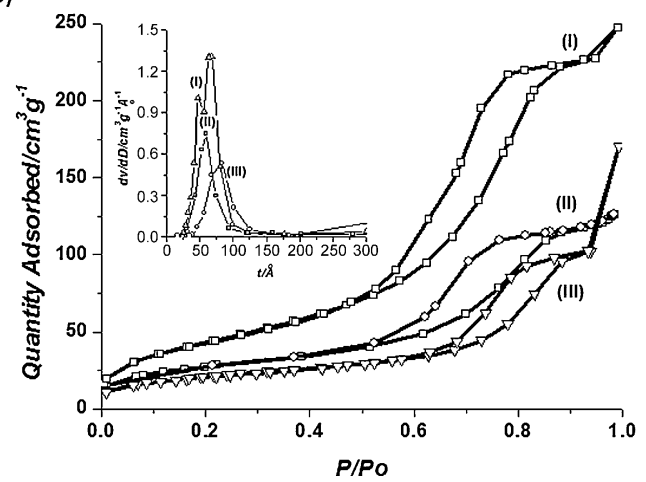

(c)

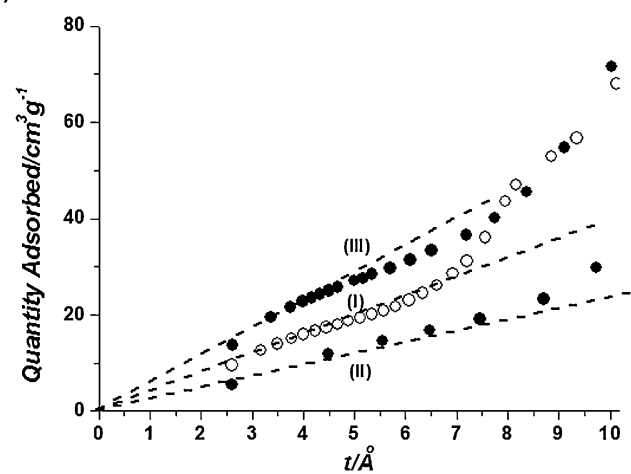

(d)

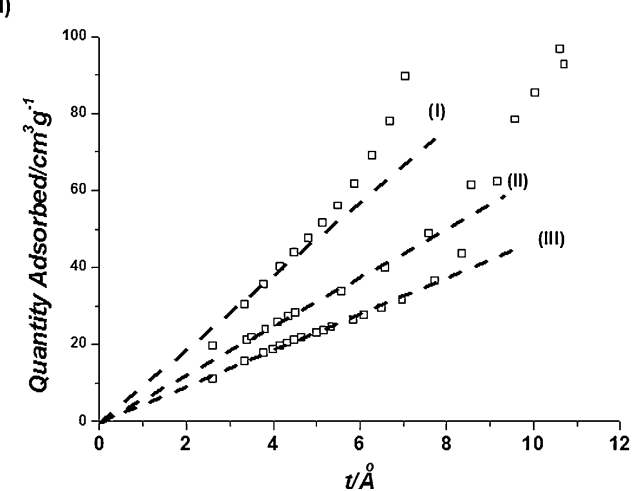

Figure 4. The $\mathrm{N}_{2}(77.4 \mathrm{~K})$ sorption isotherms with a pore-size distribution plots (the insets) before (I), partially (II), and full (III) $\mathrm{H}_{2} \mathrm{~S}$ reaction of a)meso-SiO $\mathrm{Si}_{2} @ \mathrm{CdS}-0.86$ and b) meso-SiO${ }_{2} @ \mathrm{ZnS}-0.86$ and (c and d) the t-plots of the same data in (a) and (b), respectively. 
ocity, which disappears upon partial reaction with $\mathrm{H}_{2} \mathrm{~S}$ and increases upon completion of the $\mathrm{H}_{2} \mathrm{~S}$ reaction, see Figure 4. The $\mathrm{H}_{2} \mathrm{~S}$ reaction breaks the $\mathrm{Si}-\mathrm{O}-\mathrm{Cd}$ bond and peals out the CdS nanoflakes, which create extra surface area and likely more micropores between the silica walls and nanoflakes. The BET surface area of the meso-SiO ${ }_{2}-\mathrm{ZnO}-0.86$ decreases from 175 to $75 \mathrm{~m}^{2} \mathrm{~g}^{-1}$ and the pore volume changes from 0.40 to $0.26 \mathrm{~cm}^{3} \mathrm{~g}^{-1}$ with the complete $\mathrm{H}_{2} \mathrm{~S}$ reaction. The t-plots of the meso- $\mathrm{SiO}_{2}-\mathrm{ZnO}-0.86$, meso- $\mathrm{SiO}_{2}$ ( $\mathrm{ZnO}-\mathrm{ZnS})-0.86$ (partially reacted), meso-SiO ${ }_{2} @ \mathrm{ZnS}-0.86$ samples do not display any negative deviation, indicating absence of microporosity in the $\mathrm{Zn}^{\mathrm{II}}$ samples, Figure $4 \mathrm{c}$ and $\mathrm{d}$. Note also that the percent metal oxide coating of the silica pore walls is over 90 and $35 \%$ in the meso- $\mathrm{SiO}_{2}-\mathrm{CdO}-0.86$ and $m e s o-\mathrm{SiO}_{2}-\mathrm{ZnO}-0.86$ samples, respectively. ${ }^{[32]}$ The observed difference on the isotherms between the zinc and cadmium systems must lie in the degree of coating. Further studies are required to fully elucidate the surface related changes by converting metal oxides to metal sulfides and metal selenides.

The structural details of the films were investigated using the TEM and HRTEM images of a series of samples, Figure 5. The TEM images in Figure $5 \mathrm{a}$ and $\mathrm{b}$ are obtained from the meso- $\mathrm{SiO}_{2} @ \mathrm{CdS}-0.86$ film upon complete $\mathrm{H}_{2} \mathrm{~S}$ re-
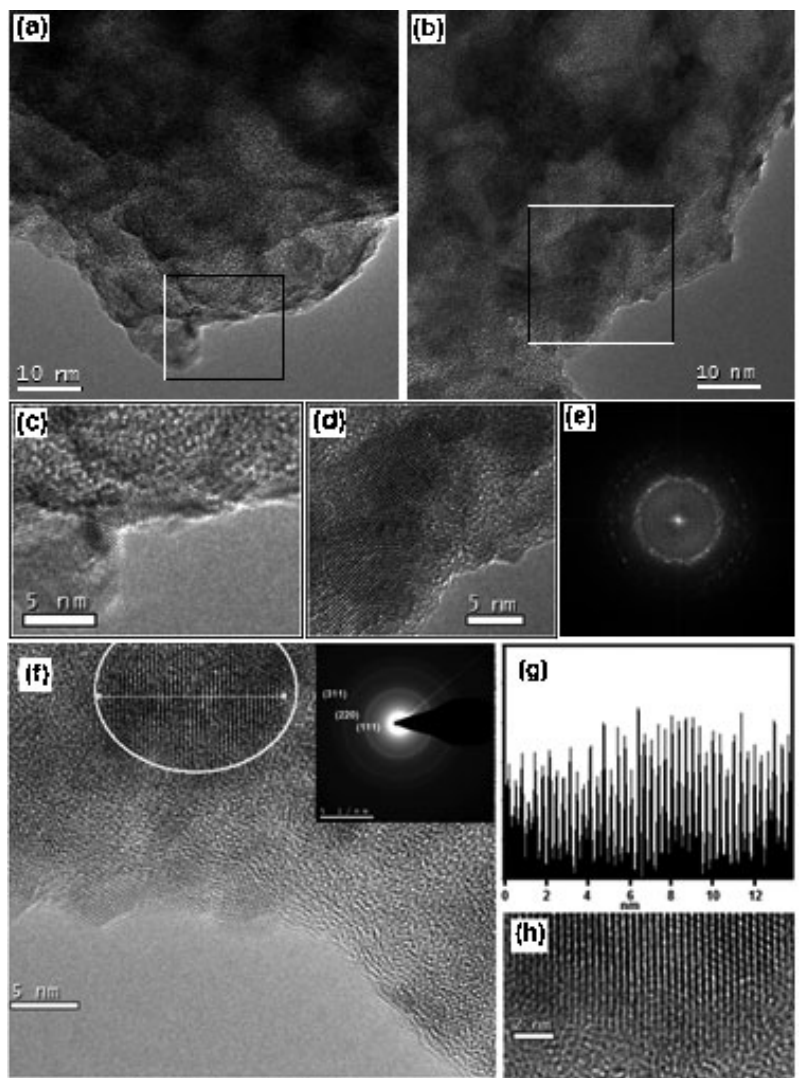

Figure 5. The TEM images of a,b) meso-SiO $@$ CdS-0.86 c and d) the amplified regions in (a) and (b). e) The FFT of the image in (b). The TEM image of meso-SiO$@ \mathrm{ZnSe}-0.86$ (inset is the SAED pattern of meso$\left.\mathrm{SiO}_{2} @ \mathrm{ZnSe}-0.86\right)$. d) The histogram along the line in the yellow circle of the image in (c). e) The HRTEM image of the yellow circle in (c). action. The image shows homogeneously distributed crystalline domains trough out the films. There are $15 \mathrm{~nm}$ and $3.0 \mathrm{~nm}$ crystalline domains all over the sample, see Figure $5 \mathrm{a}-\mathrm{e}$, due to the $\mathrm{CdS}$ nanoflakes along the pore axis and thickness axis, respectively. Since we observe a blueshift on the absorption edge of the particles that are as large as 10 $25 \mathrm{~nm}$, there must be a quantum confinement on at least one of the crystallite axis. The observed blueshift on the UV/Vis absorption-edge and the plate like crystalline CdS domains in the TEM images are consistent with the formation of the nanoflakes. The images, in Figure $5 \mathrm{c}$ and $\mathrm{d}$ are the magnified domains in the squares in the images of Figure $5 \mathrm{a}$ and $\mathrm{b}$, display lattice fringes, evenly spaced by $0.335 \mathrm{~nm}$, originating from the (111) planes $^{[35]}$ of the zinc blende CdS nanoflakes. Figure 5e shows the Fast-Fourier Transform (FFT) of the image in Figure $5 \mathrm{~b}$ showing rings due to (111), (220), and (311) planes of zinc blende CdS nanoflakes. Figure $5 \mathrm{f}$ is showing a HRTEM image of the meso- $\mathrm{SiO}_{2} @ \mathrm{ZnSe}-0.86$ sample with a selected area electron diffraction (SAED) patterns in the inset. Each ring in the SAED pattern originates from randomly distributed nanoflakes of the $\mathrm{ZnSe}$ domains in the meso- $\mathrm{SiO}_{2} @ \mathrm{ZnSe}-0.86$ sample. These rings, from inner to outer, correspond to the (111), (220), and (311) planes of the zinc blende $\mathrm{ZnSe}^{[35]}$ The distances calculated from the SAED and distances between the lattices fringes in the images (Figure $5 \mathrm{~g}$ and $\mathrm{h}$ ) are consistent with the unit cell parameters of zinc blend ZnSe. ${ }^{[35]}$ From a large group of TEM images, we found that all metal oxides are converted into metal sulfides or metal selenides, which resemble the original morphology and structure of $m e s o-\mathrm{SiO}_{2}-\mathrm{MO}-n$ thin films. ${ }^{[32]}$

The films, upon complete $\mathrm{H}_{2} \mathrm{~S}$ or $\mathrm{H}_{2} \mathrm{Se}$ reactions, were etched in a $4.0 \%$ aqueous $\mathrm{HF}$ or $2.0 \mathrm{M} \mathrm{NaOH}$ solution to further characterize the metal sulfide/metal selenide nanoflakes and to demonstrate the formation of pure mesoporous metal sulfide and metal selenide thin films. However, etching in the $\mathrm{NaOH}$ solution leaves silica contamination on the surface of the film, therefore the etching step has been carried out using dilute HF solution. The etching process of the meso- $\mathrm{SiO}_{2} @ \mathrm{ZnX}-n\left(\mathrm{X}\right.$ is $\mathrm{S}^{2-}$ or $\left.\mathrm{Se}^{2-}\right)$ films yields $\mathrm{S}$ and Se species (see Figure S1 and S2A), therefore they will not be discussed any further. Figure 6 shows an SEM and TEM images of the meso-CdS film that was scraped from the meso-SiO $\mathrm{S}_{2} @ \mathrm{CdS}-0.86$ over a glass substrate and then dropped into a $4 \% \mathrm{HF}$ aqueous solution. Notice that the etching did not alter the sponge-like surface morphology of the films, compare Figure 6 and 1. The image in Figure 6 a shows the uniformity and porosity in the film. The thickness of the film after HF treatment remained the same showing the $\mathrm{CdO}$ layers in the initial meso-SiO${ }_{2}-\mathrm{CdO}-0.86$ and the $\mathrm{CdS}$ nanoflakes, in the meso- $\mathrm{SiO}_{2} @ \mathrm{CdS}-0.86$ film are homogenously distributed. The image in Figure $6 \mathrm{~b}$ is an expanded region from the square in Figure $6 \mathrm{a}$, which shows the nanodomains with mesoporosity and the thickness of the film. TEM image shows two large nanoflakes of CdS, as the lattice fringes in each nanoflake aligned in different directions, see Figure S2B. The nanoflakes are $10-25 \mathrm{~nm}$ wide and 


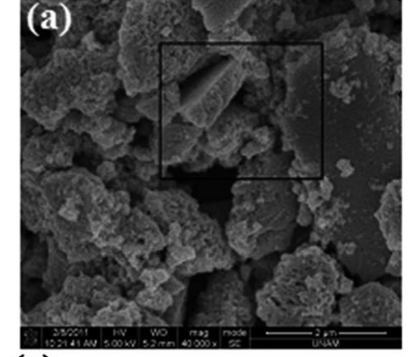

(c)
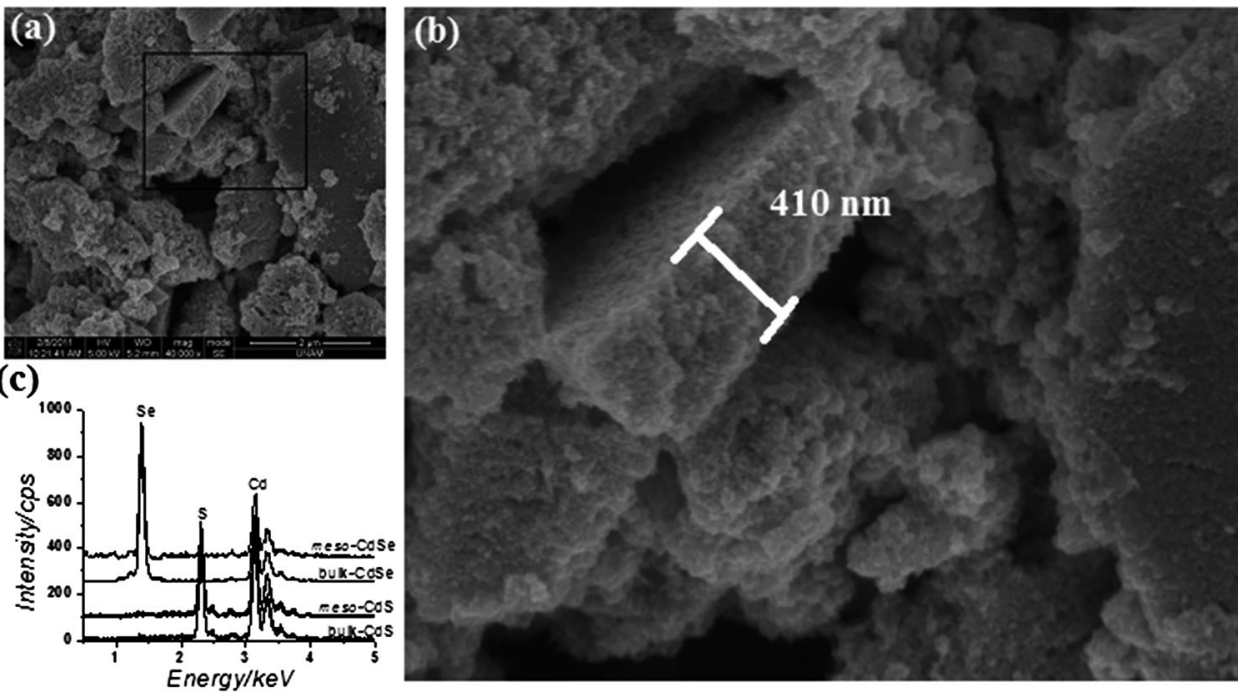

Figure 6. SEM images of meso-SiO $@$ CdS-0.86 after HF etching, meso-CdS a and b). The image in panel b) is the magnified section, marked with a red square in the left panel (a). c) The EDS spectra of meso-CdS and meso-CdSe together with their bulk counterparts.

around $3.0 \mathrm{~nm}$ thick, see Figure S2B. The lattice fringes along the lines in Figure S2B are spaced by $0.335 \mathrm{~nm}$, corresponding to the (111) planes of the zinc blende CdS lattice. Note also that the SAED patterns are also identical before and after the HF treatments, indicating that the CdS particles are as dispersed and random as before the HF treatment. Each ring from inside to out corresponds to the (111), (220), and (311) planes of the zinc blende CdS nanoflakes. The EDS measurement has been carried out on the etched samples, scraped from the film and placed over a carbon tape to ensure no silicon interference from the substrate ( $\mathrm{Si}$ wafer or glass), Figure $6 \mathrm{~b}$. The $\mathrm{Cd}$ and $\mathrm{S}$ and $\mathrm{Cd}$ and $\mathrm{Se}$ peaks perfectly overlap with each other in both samples (before and after HF etching) and with their bulk counterparts, however the Si peak totally vanished upon HF etching, see Figure $6 \mathrm{c}$. The EDS results obviously indicate that the silica walls could be removed from the media, where the $\mathrm{CdS}$ or CdSe nanoparticles remain intact and keep the film morphology.

The etched samples were further investigated using $\mathrm{N}_{2}$ sorption measurements. The $\mathrm{N}_{2}$-sorption data displays a type IV isotherm, which is characteristic of mesoporous materials. The pore shape and size distribution did not alter much upon HF etching, see Figure S2C. However, the surface area and pore volume of the etched sample dropped by $45 \%$ to $50 \mathrm{~m}^{2} \mathrm{~g}^{-1}$ and $47 \%$ to $0.16 \mathrm{~cm}^{3} \mathrm{~g}^{-1}$, respectively, due to loss of accessible silica surfaces in the samples. Figure S2D shows the t-plots of the isotherms showing some microporocity. Remember that the $\mathrm{H}_{2} \mathrm{~S}$ reaction has created the accessible silica sites in the meso-SiO $@$ @dS- 0.86 and removing silica left some micropores behind in the meso-CdS film.

The UV/Vis absorption spectra of both samples, before and after etching in a $2.0 \mathrm{~m} \mathrm{NaOH}$ solution clearly show that there is no damage on the $\mathrm{CdS}$ domains, no decomposition, no aggregation, no color change, or no further growth, see Figure S3. To improve the optical properties of meso-CdS, the grinded samples were reacted with polyethyleneimine (PEI) that is proven to be a good capping agent. ${ }^{[37]}$ Figure 7 shows photographs of PEI modified meso-CdSe (mesoCdS-PEI), PEI, and meso-CdS before modification under a $365 \mathrm{~nm}$ UV light. The PEI modified meso-CdS becomes brightly blue luminescent under UV illumination, but the others PEI and unmodified meso-CdS do not emit, see Figure $7 \mathrm{a}, \mathrm{b}$ and c. Figure $7 \mathrm{~d}$ displays a UV/Vis absorption and photoluminescence (PL) of meso-CdS-PEI in water. The tail in the absorption spectra is likely due to some scattering. The emission spectrum shows a broad PL, peaking at $455 \mathrm{~nm}$ due to band gap emission, indicating all the surface traps are modified by the PEI.

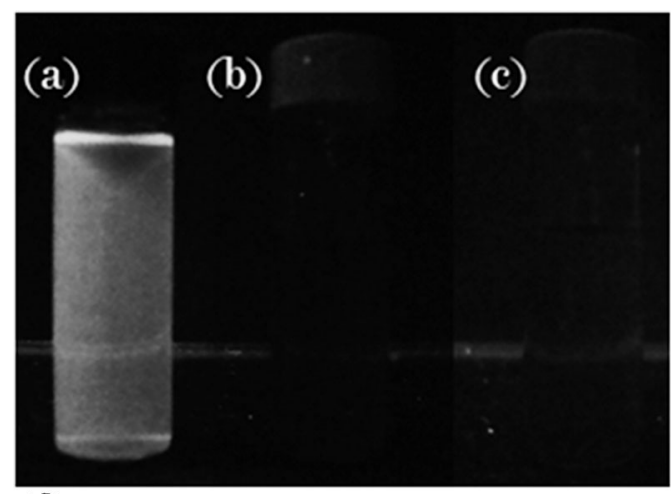

(d)

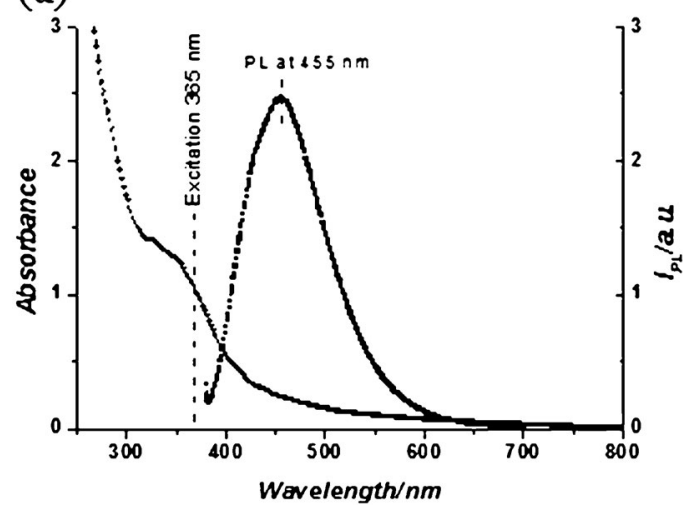

Figure 7. Photographs, under $365 \mathrm{~nm}$ UV lamb, of water dispersions of a) meso-CdS-PEI, b) PEI, and c) meso-CdS. d) The UV/Vis absorption and PL spectra of meso-CdS-PEI. 
Controlling the $\mathrm{H}_{2} \mathrm{~S}$ and $\mathrm{H}_{2} \mathrm{Se}$ reactions and metal sulfide/ selenide thickness: Notice that both the $\mathrm{H}_{2} \mathrm{~S}$ and $\mathrm{H}_{2} \mathrm{Se}$ reactions with the meso-SiO $-\mathrm{MO}-n$ are quite slow. We have employed the UV/Vis, FTIR and Raman spectroscopy and TEM imaging techniques to monitor these reactions to gather more information about the reaction mechanism and reaction kinetics between the films and the $\mathrm{H}_{2} \mathrm{~S}$ (or $\mathrm{H}_{2} \mathrm{Se}$ ) gas. For this purpose, we have chosen the $\mathrm{H}_{2} \mathrm{~S}$ reactions with the meso- $\mathrm{SiO}_{2}-\mathrm{ZnO}-0.86$ and meso-SiO$-\mathrm{CdO}-0.86$ and $\mathrm{H}_{2} \mathrm{Se}$ reaction with the meso- $\mathrm{SiO}_{2}-\mathrm{CdO}-0.86$ thin films.

Figure 8 a shows a series of FTIR spectra of a meso- $\mathrm{SiO}_{2}-$ CdO-0.86 thin film that is exposed to $\mathrm{H}_{2} \mathrm{~S}$ gas for different period of time. A similar spectral change was observed in the $\mathrm{H}_{2} \mathrm{Se}$ and meso-SiO$-\mathrm{CdO}-0.86$ reaction (not shown). The peak positions at 992 and $496 \mathrm{~cm}^{-1}$ are characteristic for the meso- $\mathrm{SiO}_{2}-\mathrm{CdO}-0.86$ samples and gradually shift to 1067 and $456 \mathrm{~cm}^{-1}$, respectively, over time, see Figure $8 \mathrm{a}$. The gradual shift in both peaks indicates that the $\mathrm{H}_{2} \mathrm{~S}$ reaction starts from the $\mathrm{CdO}$ top surface and proceeds, by the diffusion of the sulfur species, until the silica cadmium oxide interface breaks. The reaction at the interface seems to be the slowest and determining the rate of the process. Based on this proposal and the observed gradual shift on the $\tilde{v} \mathrm{Si}-\mathrm{O}$ frequency, it is reasonable to suggest that the $\tilde{\nu} \mathrm{Si}-\mathrm{O}-\mathrm{Cd}$ interface mode(s) is very sensitive to the composition and the thickness of the $\mathrm{CdO}-\mathrm{CdS}$ layers. Figure $8 \mathrm{~b}$ displays a set of resonance Raman spectra of the meso- $\mathrm{SiO}_{2}-\mathrm{CdO}-0.86$ upon exposure to the $\mathrm{H}_{2} \mathrm{Se}$ atmosphere. The peaks due to Raman active LO modes gradually increase in intensity and shift to higher energy and become relatively sharper over time. Both blueshift (from 202.5 to $205.8 \mathrm{~cm}^{-1}$ ) and decrease on the full-width-half-maximum (from 19.2 to $17.2 \mathrm{~cm}^{-1}$ ) of the $1 \mathrm{LO}$ mode at around $205 \mathrm{~cm}^{-1}$ also indicates the growth of the CdSe nanoislands over time. However, the $\mathrm{H}_{2} \mathrm{~S}$ and meso- $\mathrm{SiO}_{2}-\mathrm{ZnO}-0.86$ reaction proceeds quite differently, see Figure $8 \mathrm{c}$. It seems that the silica zinc oxide interface is as reactive as the $\mathrm{ZnO}$ domains (see below), but overall the reaction is slow.

Further information has been gathered from the spectral changes in the UV/Vis absorption and EDS spectra. The $\mathrm{UV} / \mathrm{Vis}$ absorption spectra and EDS data were collected from the same samples, used for the FTIR measurements. The two representative sets of UV/Vis absorption spectra are shown inFigure $9 \mathrm{a}$ and $\mathrm{b}$, one set from CdSe and one set from the CdS systems. With an increasing exposure time, the absorption-edge of all the meso-SiO${ }_{2} @ \mathrm{CdS}$ and meso$\mathrm{SiO}_{2} @ \mathrm{CdSe}$ gradually redshifts to the absorption-edge, recorded for the same sample upon completion of the $\mathrm{H}_{2} \mathrm{~S}$ or $\mathrm{H}_{2} \mathrm{Se}$ reactions, see Figure $9 \mathrm{a}$, and b. Therefore, these observations are consistent with the Raman observations and indicative of the growth of the chalcogenites. The evaluated band gaps and thickness calculated using Brus's expression ${ }^{[36]}$ were also plotted against the $\mathrm{H}_{2} \mathrm{~S}$ and $\mathrm{H}_{2} \mathrm{Se}$ exposure time (Figure 9c and d). The spectral changes and evaluated thickness of the CdS and CdSe nanoflakes clearly show that the process is diffusion and interface limited, where the interface determines the completion of the reaction. The plot of the $\mathrm{CdS}$ thickness in the meso-SiO ${ }_{2}-(\mathrm{CdO}-\mathrm{CdS})-0.86$ versus time fits best with three exponential functions and a constant. The constant is the thickness upon completion of the reaction and determined to be $2.8 \mathrm{~nm}$. This thickness is consistent with the thickness calculated using the UV/Vis spectrum of the same sample after complete reaction. Each exponential function corresponds to a different rate and a different reaction, namely the reactions between the $\mathrm{H}_{2} \mathrm{~S}$ and $\mathrm{CdO}$ nanoisland surface (fastest), and bulk of the nanoislands (moderate), and the silica-nanoisland interface (slow, based on the spectral changes in the FTIR spectra with time), see the inset in Figure $9 \mathrm{~d}$. The EDS spectra of the samples at each stage of the $\mathrm{H}_{2} \mathrm{~S}$ and $\mathrm{H}_{2} \mathrm{Se}$ reactions were also recorded and analyzed to further understand how the $\mathrm{ZnS}$, CdS, and CdSe formation proceeds. The EDS spectra display a gradual increase of the $\mathrm{S}$ or Se peaks while the $\mathrm{Si}$ and $\mathrm{Cd}$ or $\mathrm{Si}$ and $\mathrm{Zn}$ signals remain constant during the $\mathrm{H}_{2} \mathrm{~S}$ or $\mathrm{H}_{2} \mathrm{Se}$ reactions, see Figure $9 \mathrm{e}, \mathrm{f}, \mathrm{S} 4 \mathrm{~A}$, and S4B. A similar exponential increase in the S/Zn EDS intensity ratio (as of gradual increase on the UV/Vis absorption edge) has been observed upon exposing the meso- $\mathrm{SiO}_{2}-\mathrm{ZnO}-0.86$ thin films to the $\mathrm{H}_{2} \mathrm{~S}$ atmosphere (Figure S4C and S4D). However, the best fit of the EDS S/Zn intensity ratio has double exponential components with a constant of 0.39 ; notice that
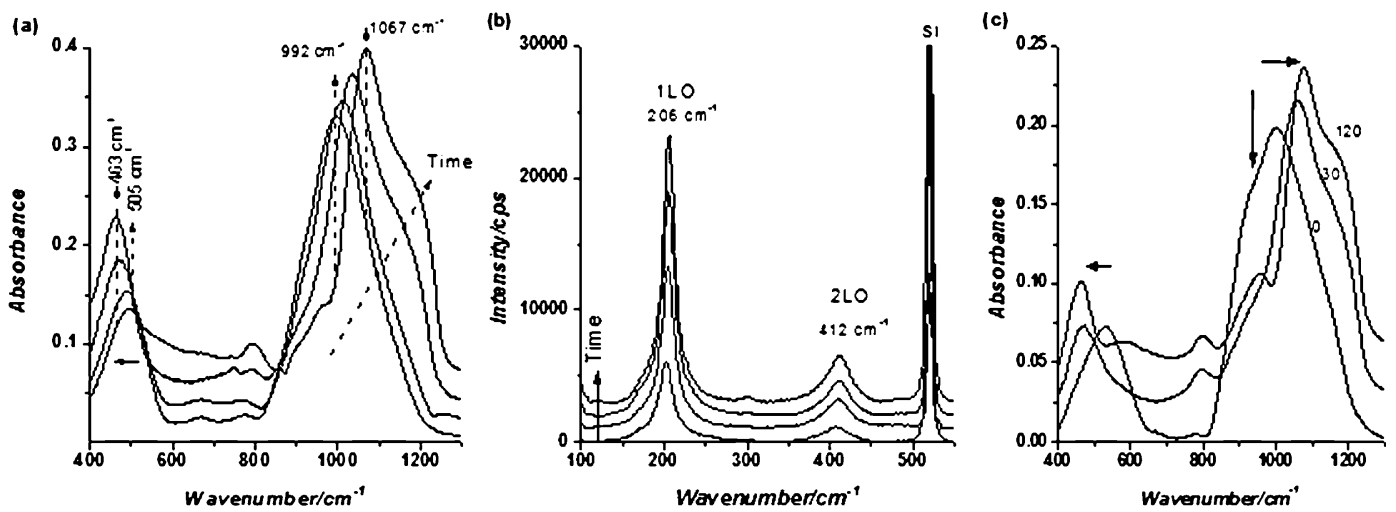

Figure 8. a) FTIR spectral changes during $\mathrm{H}_{2} \mathrm{~S}$ reaction of the meso- $\mathrm{SiO}_{2}-\mathrm{CdO}-0.86$ film to meso- $\mathrm{SiO}_{2} @ \mathrm{CdS}-0.86$ film and b) The Raman spectral changes during $\mathrm{H}_{2} \mathrm{Se}$ reaction of the meso- $\mathrm{SiO}_{2}-\mathrm{CdO}-0.86$ film to meso-SiO $\mathrm{O}_{2} @ \mathrm{CdSe}-0.86$ film. c) FTIR Spectral changes during $\mathrm{H}_{2} \mathrm{~S}$ reaction of the meso-SiO${ }_{2}$ $\mathrm{ZnO}-0.86$ film to meso-SiO $2 @ \mathrm{ZnS}-0.86$ film. 

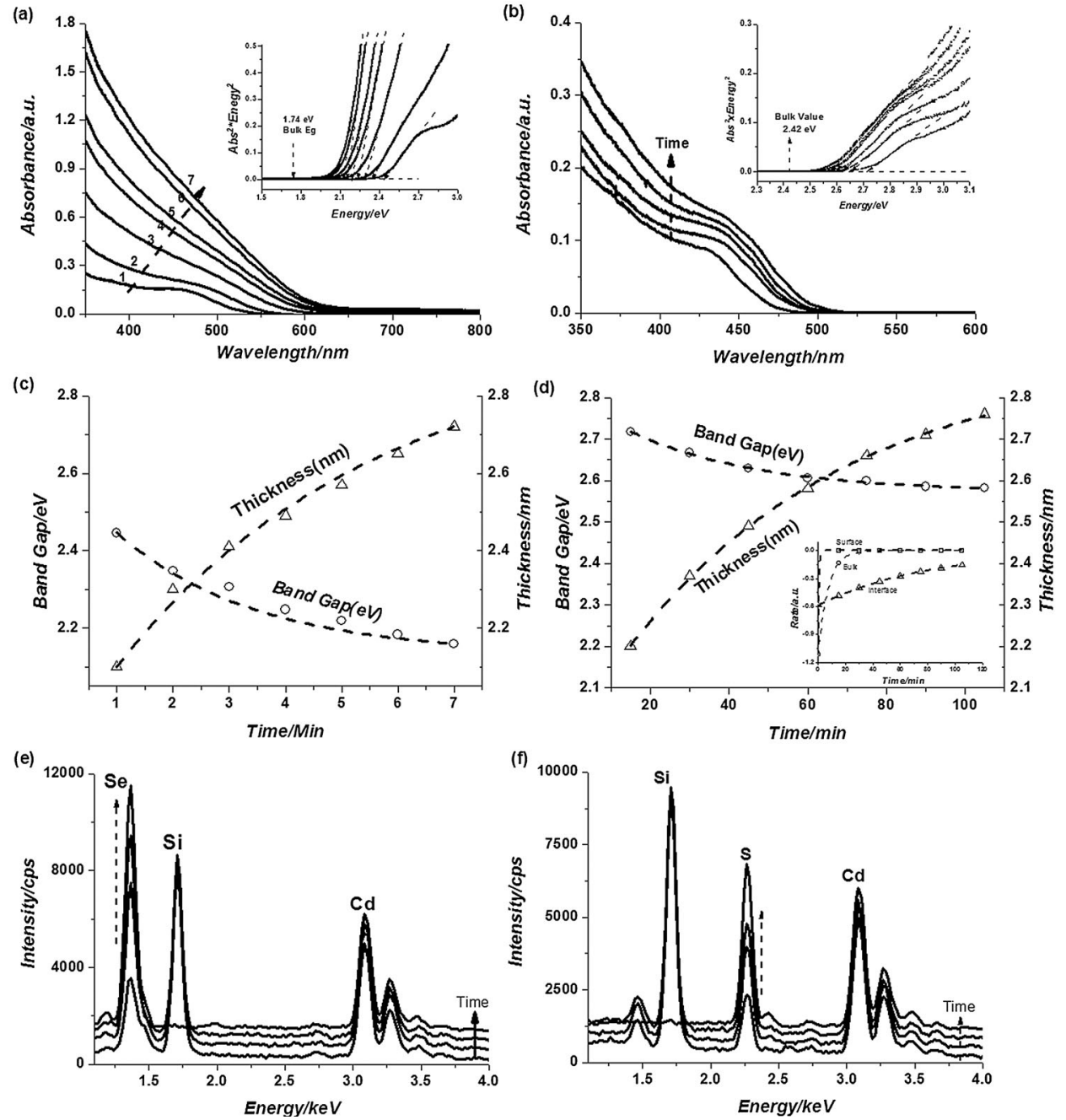

Figure 9. UV/Vis spectral changes during a) $\mathrm{H}_{2} \mathrm{Se}$ and b) $\mathrm{H}_{2} \mathrm{~S}$ reactions with meso-SiO$-\mathrm{CdO}-0.86$ thin films The band-gap values and thickness of the nanoislands versus time plots of the c) $m e s o-\mathrm{SiO}_{2} @ \mathrm{CdSe}-0.86$ and d) meso- $\mathrm{SiO}_{2} @ \mathrm{CdS}-0.86$ (inset is the convolution of the thickness versus time plot). The EDS spectra of meso$\mathrm{SiO}_{2}$-CdO-0.86 with time under an atmosphere of e) $\mathrm{H}_{2} \mathrm{Se}$ and f) $\mathrm{H}_{2} \mathrm{~S}$ (top EDS spectra are the bulk CdSe and $\mathrm{CdS}$ ). above thicknesses and cannot be observed by the current methods. To evaluate the $D_{\mathrm{o}}$, we carried out the meso- $\mathrm{SiO}_{2}$ CdO-0.86 and $\mathrm{H}_{2} \mathrm{Se}$ reaction using smaller amount of $\mathrm{H}_{2} \mathrm{Se}$ and collected the UV/Vis absorption spectra with a smaller intervals. Figure S5 shows the spectra and related data. The UV/Vis data shows that the initial reaction is fast; first a few CdSe layers form almost immediately, up to a thickness of about $1.4-1.5 \mathrm{~nm}$. This is consistent with the estimate above.

Therefore, the silica cadmium oxide interface is the least reactive and determines the completion of the reaction. Based on the EDS, FTIR, and UV/Vis absorption spectral changes, it can be speculated that at each intermediate stage of the reaction, we have mesoporous silica cadmium oxide cadmium sulfide (or cadmium selenide) in the sponge-like mesoporous thin films (denoted as meso$\mathrm{SiO}_{2}-(\mathrm{CdO}-\mathrm{CdS}($ or $\mathrm{CdSe}))-n$ and meso- $\mathrm{SiO}_{2}-(\mathrm{ZnO}-\mathrm{ZnS}$ (or $\mathrm{ZnSe})$ )- $n$ ) with a decreasing metal oxide thickness in time.

To further confirm the above proposal, we have also collected TEM images from three different sets of samples, namely this constant is the $\mathrm{S} / \mathrm{Zn}$ intensity ratio in the bulk $\mathrm{ZnS}$, indicating the completion of the reaction, Figure S4C.

Huang et al. ${ }^{[38]}$ has observed a similar particle size versus time behavior of crystal growth during hydrothermal coarsening of mercatoethanol capped $\mathrm{ZnS}$. The nanocrystal growth can be described by $D-D_{\mathrm{o}}=k t^{1 / n}$, where $D$ and $D_{\text {o }}$ are particles size of the growing particle at time $t$, and $t_{\mathrm{o}}$ (at beginning of the process), $k$ is a material constant and $1 / n$ is related to the growth mechanism. If $n$ is equal to 3 , it indicates that the growth is controlled by the volume diffusion of ions in the matrix. It is also the likely mechanism for our reaction. The linear fit of the plot $\ln \left(D-D_{\mathrm{o}}\right)$ versus $\ln (t)$ provides $n$ of 3.0 for both $\mathrm{H}_{2} \mathrm{~S}$ and $\mathrm{H}_{2} \mathrm{Se}$ reactions, if the $D_{\text {o }}$ is $1.44 \mathrm{~nm}$ for CdSe and $1.50 \mathrm{~nm}$ for the CdS, Figure 10. It is likely that, at these thicknesses, the $\mathrm{CdO}$ layers are fully coated and inaccessible for the further $\mathrm{H}_{2} \mathrm{~S}$ or $\mathrm{H}_{2} \mathrm{Se}$ gas reaction and the reactions slow. Therefore, it is quite reasonable to suggest that the reactions are very fast up to the

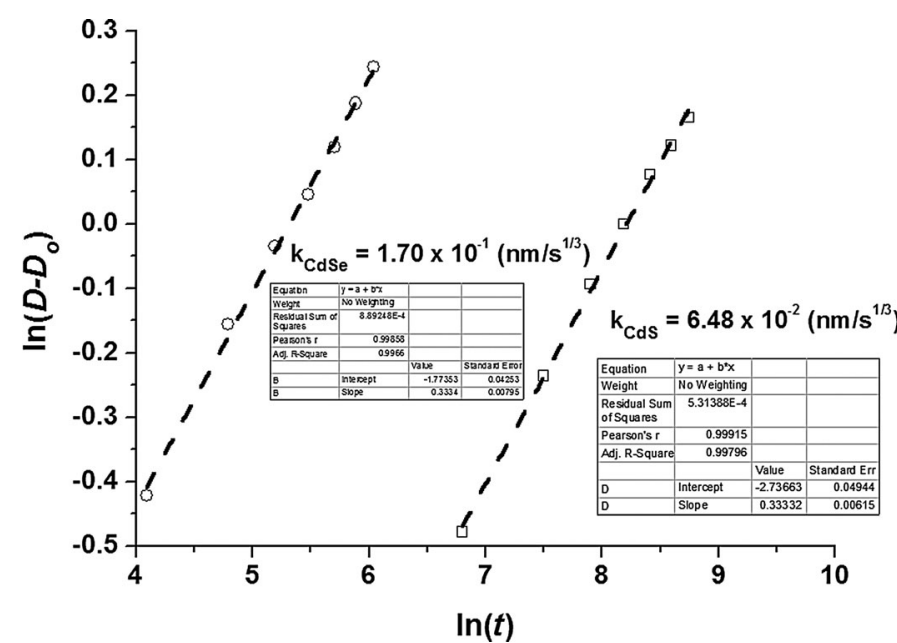

Figure $10 . \ln \left(\mathrm{D}-D_{\mathrm{o}}\right)$ versus $\ln (t)$ plots of the time dependent thickness data of meso-SiO$-(\mathrm{CdO}-\mathrm{CdSe})-0.86$ and meso-SiO${ }_{2}-(\mathrm{CdO}-\mathrm{CdS})-0.86$. 
meso- $\mathrm{SiO}_{2}-(\mathrm{CdO}-\mathrm{CdS})-0.86, \quad$ meso-SiO $-(\mathrm{CdO}-\mathrm{CdSe})-0.86$, and $m e s o-\mathrm{SiO}_{2}-(\mathrm{ZnO}-\mathrm{ZnSe})-0.86$ before and after completion of the $\mathrm{H}_{2} \mathrm{~S}$ and $\mathrm{H}_{2} \mathrm{Se}$ reactions, see Figure 11. A TEM image of the meso-SiO $-\mathrm{ZnO}-0.86$ is also shown in Figure $10 \mathrm{a}$ for comparison purpose. Figure $11 \mathrm{~b}$, e, and f show the TEM images of the partially reacted samples of meso$\mathrm{SiO}_{2}-(\mathrm{ZnO}-\mathrm{ZnSe})-0.86$, meso- $\mathrm{SiO}_{2}-(\mathrm{CdO}-\mathrm{CdS})-0.86$, and meso- $\mathrm{SiO}_{2}-(\mathrm{CdO}-\mathrm{CdSe})-0.86$, respectively. The sponge-like, a few nanometer thick, and relatively darker regions in the images display lattice fringes, originating from the crystalline metal sulfide or metal selenides nanoislands. The crystalline domains follow the pattern of the silica walls as in the metal oxides; compare images in Figure 11 a with b, e, and f. As proposed using spectroscopic techniques, the reactions proceed from the top surface of the oxide nanoislands until they break the Si-O-M interface, which is less reactive and requires a longer $\mathrm{H}_{2} \mathrm{~S}$ or $\mathrm{H}_{2} \mathrm{Se}$ exposure time. Breaking the $\mathrm{M}-\mathrm{O}-\mathrm{Si}$ bond at the interface changes the overall morphology of the films at the meso-scale, but does not change at the
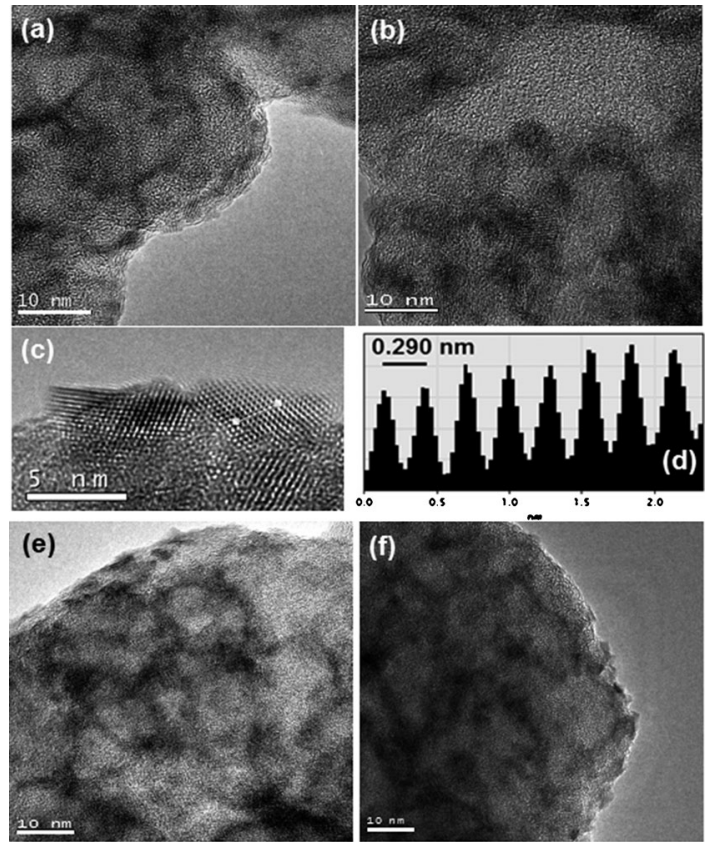

Figure 11. TEM images of the meso-SiO$-\mathrm{ZnO}-0.86$ a) before and b) after partially $\mathrm{H}_{2} \mathrm{Se}$ reacted (meso- $\left.\mathrm{SiO}_{2}-(\mathrm{ZnO}-\mathrm{ZnSe})-0.86\right)$ films. The TEM images of the partially reacted meso-SiO $2-\mathrm{CdO}-0.86$ film c) a HRTEM image, d) histogram along the line in c) and e) the TEM. f) The TEM image of the meso- $\mathrm{SiO}_{2}-(\mathrm{CdO}-\mathrm{CdSe})-0.86$ films. micron-scale; compare the TEM images in Figure 5 and 11. A representative HRTEM image of the meso- $\mathrm{SiO}_{2}-(\mathrm{CdO}-$ CdSe)-0.86 and its analysis (along the line in Figure 11c) are shown in Figure 11c and d, respectively. The same lattice fringes were observed in the partially and completely reacted samples in their HRTEM images. The spacing between the lines are $0.290 \mathrm{~nm}$, corresponding to the (200) planes of the crystalline zinc blende CdSe. In some parts of the samples, the (111) lattice fringes are also observed from both (partially and completely reacted) sets of samples. All these observations are consistent with our top to interface diffuse controlled reaction mechanism.

Scheme 1 is a schematic representation of a reaction between the $\mathrm{H}_{2} \mathrm{Se}$ gas and meso- $\mathrm{SiO}_{2}-\mathrm{CdO}$ film and summarizes the overall process. The black regions, representing the nanocrystalline islands of $\mathrm{CdO}$ domains over the silica pore walls that react with $\mathrm{H}_{2} \mathrm{Se}$ gas to produce intermediate meso- $\mathrm{SiO}_{2}-(\mathrm{CdO}-\mathrm{CdSe})$ films. The black regions are unreacted $\mathrm{CdO}$ domains between the silica wall and CdSe interface and the gray domains are nanocrystalline CdSe, see middle sketch. The last sketch in the Scheme is the final product upon the completion of the $\mathrm{H}_{2} \mathrm{Se}$ reaction, where the Si-O-Cd interface reacts with selenium and breaks; as a result the CdSe nanoislands peal out from the silica surface as nanoflakes.

\section{Conclusion}

The meso-SiO $2-\mathrm{MO}-n$ (where $\mathrm{M}$ is $\mathrm{Zn}^{\mathrm{II}}$ or $\mathrm{Cd}^{\mathrm{II}}$ ) thin films can be reacted with $\mathrm{H}_{2} \mathrm{~S}$ or $\mathrm{H}_{2} \mathrm{Se}$ at RT to obtain mesoporous metal sulfide or metal selenide thin films, respectively, where the CdSe to silica ratio can be as high as $79 \% \mathrm{w} / \mathrm{w}$. The $\mathrm{H}_{2} \mathrm{~S}$ or $\mathrm{H}_{2} \mathrm{Se}$ reactions take place from the top surface of the oxides and finish upon reaction of the metal ion at the silica metal oxide interface, giving nanoflakes of metal sulfides or metal selenides, respectively. The silica metal oxide interface breaks upon completion of the reactions. However, the reactions can be stopped to obtain mesoporous silica metal oxide metal sulfide or silica metal oxide metal selenide thin films. The initial reactions are fast and produce a few atomic layers of chalcogenites that likely block and slow the volume diffusion ions and as a result the overall process. The pure mesoporous CdS and CdSe can be obtained by etching the silica domains by a dilute HF aque-

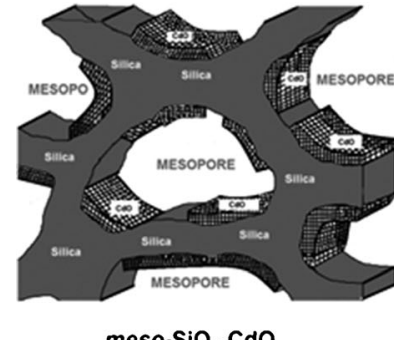

meso-SiO $-\mathrm{CdO}$
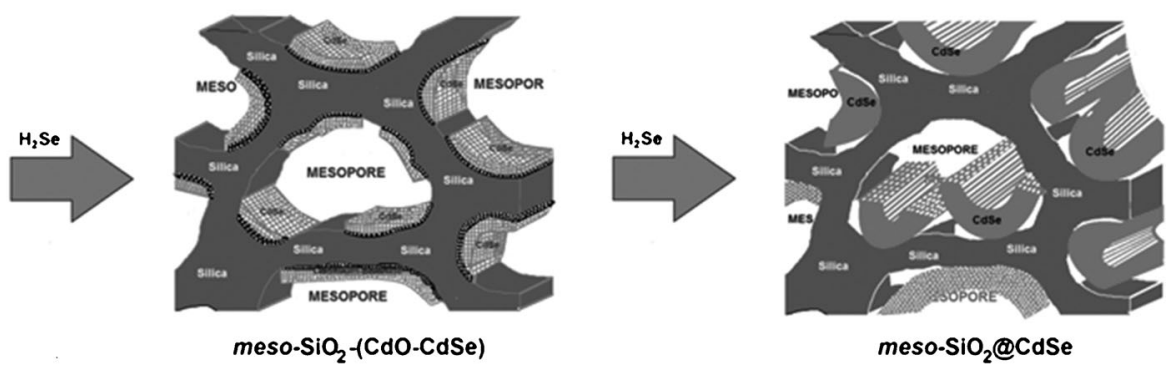

Scheme 1. Schematic representation of the synthesis path for the $\mathrm{H}_{2} \mathrm{Se}$ and meso-SiO $2-\mathrm{CdO}$ reaction. 
ous solution. The meso-CdS display bright blue PL upon surface modification with PEI. The method developed here can also be adapted to other metal oxides and mixed metal oxides, which can be used to obtain their mesoporous metal sulfide, metal selenide, and metal telluride thin films for various applications.

\section{Experimental Section}

Preparation of meso-SiO silica metal oxides were prepared as described in reference 32 and represented as meso- $\mathrm{SiO}_{2}-\mathrm{MO}-n$ (where $\mathrm{M}$ is either $\mathrm{Zn}^{\mathrm{II}}$ or $\mathrm{Cd}^{\mathrm{II}}$ and $n$ is metal oxide to silica mole ratio and is $0.29,0.57,0.86$, and 1.14).

Preparation of meso-SiO${ }_{2}$-(MO-MS)-n and meso-SiO $@ \mathrm{MS}-n$ thin films: Insert the calcined meso-SiO $-\mathrm{ZnO}-n$ or $m e s o-\mathrm{SiO}_{2}-\mathrm{CdO}-n$ thin films into a vacuum chamber and evacuate the chamber for $2 \mathrm{~min}$. Expose the samples to 300 Torr $\mathrm{H}_{2} \mathrm{~S}$ gas either desired period or until complete reaction (see below) to obtain meso- $\mathrm{SiO}_{2}-\mathrm{ZnO}-\mathrm{ZnS}$ and meso-SiO ${ }_{2}-\mathrm{CdO}-\mathrm{CdS}$ or meso-SiO${ }_{2} @ \mathrm{ZnS}-n$ and meso-SiO${ }_{2} @ \mathrm{CdS}-n$, thin films, respectively. Then, pump out the unreacted excess $\mathrm{H}_{2} \mathrm{~S}$ gas from the reaction media for $5 \mathrm{~min}$ before removing the sample from the reaction chamber. The meso$\mathrm{SiO}_{2}-\mathrm{ZnO}-\mathrm{ZnS}$ and meso-SiO${ }_{2}-\mathrm{CdO}-\mathrm{CdS}$ samples were repeatedly exposed in several steps to the same atmosphere and monitored using UV/ Vis and EDS spectroscopy.

Preparation of meso-SiO $-(\mathrm{MO}-\mathrm{MSe})-n$ and meso-SiO $@ \mathrm{MSe}-n$ thin films: Insert the calcined meso- $\mathrm{SiO}_{2}-\mathrm{ZnO}-n$ or $m e s o-\mathrm{SiO}_{2}-\mathrm{CdO}-n$, thin films into a vacuum chamber and evacuate the chamber for $2 \mathrm{~min}$. Expose the meso- $\mathrm{SiO}_{2}-\mathrm{ZnO}-n$ and $m e s o-\mathrm{SiO}_{2}-\mathrm{CdO}-n$ samples to 300 Torr of $5 \% \mathrm{H}_{2} \mathrm{Se}$ gas (diluted with pure $\mathrm{N}_{2}$ gas) for $1 \mathrm{~h}$ for a complete reaction to obtain meso-SiO${ }_{2} @ \mathrm{ZnSe}-n$ and $m e s o-\mathrm{SiO}_{2} @ \mathrm{CdSe}-n$, thin films, respectively or repeatedly exposed to the same atmosphere, several times within $1 \mathrm{~h}$ to obtain partially reacted $m e s o-\mathrm{SiO}_{2}-\mathrm{ZnO}-\mathrm{ZnSe}$ and meso$\mathrm{SiO}_{2}-\mathrm{CdO}-\mathrm{CdSe}$ samples. Then, first evacuate the unreacted $\mathrm{H}_{2} \mathrm{Se}$ gas into a $\mathrm{Cu}^{\mathrm{II}}$ loaded mesoporous silica for 2 min to convert the excess $\mathrm{H}_{2} \mathrm{Se}$ into copper selenide species. Then, evacuate the reaction chamber by pumping using a rotary pump for $5 \mathrm{~min}$.

Preparation of the meso-CdS and meso-CdSe thin films: Dip the meso$\mathrm{SiO}_{2} @ \mathrm{MS}$ (or MSe, $\mathrm{M}$ is $\mathrm{Zn}^{\mathrm{II}}$ or $\mathrm{Cd}^{\mathrm{II}}$ ) film into $10 \mathrm{~mL} 4 \% \mathrm{HF}$ solution for 1 second. Then, remove and wash the film with deionized water and dry it at RT. For the powder samples, first obtain the powder samples by scraping the films from the glass slides and then immerse the powder into a $10 \mathrm{~mL} 4 \% \mathrm{HF}$ solution for a few minutes. Following that centrifuge and decent the solution into an HF disposal container. Add deionized water and repeat the centrifugation and decantation step several times to wash out all the fluoride species. Then dry the powder in a $100^{\circ} \mathrm{C}$ oven overnight.

Surface modification of meso-CdS with PEI: $1 \mathrm{mg}$ of $\mathrm{HF}$ acid etched meso-CdS and excess amount of PEI (polyethyleneimine) are dissolved in absolute ethanol. The PEI and meso-CdS solution was kept in a sonicator for $5 \mathrm{~min}$. Evaporation of the solvent give photoluminecent (PL) PEI modified meso-CdS (denoted as meso-CdS-PEI). The PL was measured upon dispersion of meso-CdS-PEI in deionized water.

Characterization: The Fourier transform infrared (FTIR) spectra were recorded using a Bruker Tensor 27 model FTIR spectrometer. A Digi Tect TM DLATGS detector was used with a resolution of $4.0 \mathrm{~cm}^{-1}$ in the $400-4000 \mathrm{~cm}^{-1}$ range. The spectra were recorded using the samples using dry $\mathrm{KBr}$ pallets. The UV/Vis absorption spectra were recorded using thin films coated over quartz or glass substrates and using a Thermo Scientific Evolution 300/600 UV/Vis spectrometer. The micro-Raman spectra were recorded on a LabRam confocal Raman microscope with a $300 \mathrm{~mm}$ focal length. The spectrometer is equipped with a Ventus LP $53250 \mathrm{~mW}$, diode-pumped solid-state laser operated at $20 \mathrm{~mW}$, with a polarization ratio of 100:1 and a wavelength of a $532.1 \mathrm{~nm}$ and a $1024 \times 256$ element CCD camera. The signal collected was transmitted via a fiber optic cable into a spectrometer with a $1800 \mathrm{~g} \mathrm{~mm}^{-1}$ grating. The Raman spectra were collected by manually placing the probe tip near the desired point of the sample on a silicon wafer. The x-ray diffraction (XRD) patterns were recorded on a Rigaku Miniflex Diffractometer using a high power $\mathrm{Cu}_{\mathrm{K} \alpha}$ source operating at $30 \mathrm{kV} / 15 \mathrm{~mA}$. The polarized optical microscopy (POM) images were obtained in transmittance mode on a ZEISS Axio Scope A1 Polarizing Optical Microscope. The scanning electron microscopy (SEM) images and energy dispersive x-ray spectroscopy (EDS) data were collected using ZEISS EVO-40 operating at $15 \mathrm{kV}$ and the same microscope using Bruker AXS XFlash detector 4010, respectively. The high resolution SEM images were recorded using FEI Nova 600i NanoLab Dual Beam TM-SEM. The high resolution transmittance electron microscope (HRTEM) images were recorded on a FEI Technai G2 F30 at an operating voltage of $200 \mathrm{kV}$. The film samples were scribed and ground well in a mortar using $5 \mathrm{~mL}$ of ethanol and dispersed using a sonicator for $5 \mathrm{~min}$. One drop of the dispersed ethanol solution was put on a TEM grid and dried over a hot-plate. The $\mathrm{N}_{2}(77.4 \mathrm{~K})$ sorption measurements were performed with a TriStar 3000 automated gas adsorption analyzer (Micrometrics) in a relative pressure range, $P / P_{0}$, from 0.01 to 0.99 . To provide high accuracy and precision in the determination of $P / P_{0}$, the saturation pressure $P_{0}$ was measured over 120 min intervals. The powder sample, which was obtained by scraping about 20 glass slides of each film samples, was dehydrated under (ca. $10^{-2}$ Torr) vacuum for $3 \mathrm{~h}$ at $250^{\circ} \mathrm{C}$ to remove adsorbed water and other volatile species from the pores before the $\mathrm{N}_{2}$ sorption measurements were recorded. The PL of the meso-CdS-PEI that is dispersed in deionized water in a quartz cell was measured using Varian Cary Eclipse fluorescence spectrophotometer. An excitation wavelength of $365 \mathrm{~nm}$ was used and the PL is from 380 to $700 \mathrm{~nm}$. The excitation and emission slit widths were both set to $10 \mathrm{~nm}$.

\section{Acknowledgements}

The financial support of TÜBITAK under the project $110 \mathrm{~T} 813$ and the Turkish Academy of Science are deeply appreciated. We also thank to Mustafa Güler for the TEM images.

[1] G. A. Ozin, A. C. Arsenault, L. Cademartiti, Nanochemistry: A Chemical Approach to Nanomaterials, 2nd ed., Royal Society of Chemistry, Cambridge, 2009.

[2] X. Zhang, H. Chen, H. Y. Zhang, Chem. Commun. 2007, 1395.

[3] B. O. Dabbousi, J. Rodriguez Viejo, F. V. Mikulec, J. R. Heine, H. Mattoussi, R. Ober, K. F. Jensen, M. G. Bawendi, J. Phys. Chem. B 1997, 101, 9463.

[4] X. G. Peng, M. C. Schlamp, A. V. Kadavanich, A. P. Alivisatos, J. Am. Chem. Soc. 1997, 119, 7019.

[5] Z. Y. Tang, Z. L. Zhang, Y. Wang, S. C. Glötzer, N. A. Kotov, Science 2006, 314, 274.

[6] Y. Wang, A. S. Angelatos, F. Caruso, Chem. Mater. 2008, 20, 848

[7] A. Kongkanand, K. Turdy, K. Takechi, M. Kuno, P. V. Kamat, J. Am. Chem. Soc. 2008, 130, 4007.

[8] J. C. Kim, J. Choi, Y. B. Lee, J. H. Hong, J. I. Lee, J. W. Yang, W. I. Lee, N. H. Hur, Chem. Commun. 2006, 48, 5024

[9] F. Schüth, Angew. Chem. 2003, 115, 3730; Angew. Chem. Int. Ed. 2003, 42, 3604.

[10] H. F. Yang, D. Y. Zhao, J. Mater. Chem. 2005, 15, 1217.

[11] M. Tiemann, Chem. Mater. 2008, 20, 961.

[12] F. Gao, Q. Y. Lu, D. Y. Zhao, Adv. Mater. 2003, 15, 739.

[13] C. Tura, N. Coombs, Ö. Dag, Chem. Mater. 2005, 17, 573.

[14] Y. Shi, Y. Wan, R. Liu, B. Tu, D. Y. Zhao, J. Am. Chem. Soc. 2007, 129, 9522.

[15] H. Parala, H. Winkler, M. Kolbe, A. Wohlfart, R. A. Fischer, R. Schechel, H. von Seggern, Adv. Mater. 2000, 12, 1050.

[16] W. H. Zhang, J. L. Shi, H. R. Chen, Z. L. Huo, D. S. Yan, Chem. Mater. 2001, 13, 648.

[17] D. Wang, H. P. Jakobson, R. Kou, J. Tang, R. Z. Fineman, D. Yu, Y. Lu, Chem. Mater. 2006, 18, 4231.

[18] H. İ. Okur, Y. Türker, Ö. Dag, Langmuir 2010, 26, 538. 
[19] Y. Wang, Z. Wu, L. Shi, J. Zhu, Adv. Mater. 2005, 17, 323.

[20] Q. Jiang, Z. Y. Wu, Y. M. Wang, Y. Cao, C. F. Zhou, J. H. Zhu, J. Mater. Chem. 2006, 16, 1536.

[21] W.-H. Tian, L.-B. Sun, X.-L. Song, X.-Q. Liu, Y. Yin, G.-S. He, Langmuir 2010, 26, 17398.

[22] P. V. Braun, P. Osenar, S. I. Stupp, Nature 1996, 380, 325.

[23] R. K. Rana, L. Zhang, J. C. Yu, Y. Mastai, A. Gedanken, Langmuir 2003, 19, 5904.

[24] Ö. Dag, S. Alayoğlu, C. Tura, Ö. Çelik, Chem. Mater. 2003, 15, 2711.

[25] J. S. Hu, L. L. Ren, Y. G. Guo, H. P. Liang, A. M. Cao, L. J. Wan, C. L. Bai, Angew. Chem. 2005, 117, 1295; Angew. Chem. Int. Ed. 2005, 44, 1269.

[26] Y. Türker, Ö. Dag, J. Mater. Chem. 2008, 18, 3467.

[27] J. L. Mohanan, I. U. Arachchige, S. L. Brock, Science 2005, 307, 397.

[28] I. U. Arachchige, S. L. Brock, J. Am. Chem. Soc. 2006, 128, 7964.

[29] H. Yu, S. L. Brock, ACS Nano 2008, 2, 1563.

[30] S. Bag, I. U. Arachchige, M. G. Kanatzidis, J. Mater. Chem. 2008, 18 , 3628 .
[31] C. Albayrak, N. Özkan, Ö. Dag, Langmuir 2011, 27, 870

[32] C. Karakaya, Y. Türker, C. Albayrak, Ö. Dag, Chem. Mater. 2011 23,3062 .

[33] A. Dinger, M. Göppert, R. Becker, M. Grün, S. Petillon, C. Klingshirn, J. Liang, V. Wagner, J. Geurts, Phys. Rev. B 2001, 64, 245310.

[34] A. D. Yoffe, Adv. Phys. 2001, 50,1.

[35] O. Zakharov, A. Rubio, X. Blasé, M. L. Cohen, S. G. Louie, Phys. Rev. B 1994, 50, 10780.

[36] L. Brus, J. Phys. Chem. 1986, 90, 2555.

[37] O. E. Rayevska, G. Y. Grodzyuk, V. M. Dzhagan, O. L. Stroyuk, S. Y. Kuchmiy, V. F. Plyusnin, V. P. Grivin, M. Y. Valakh, J. Phys Chem. C 2010, 114, 22478.

[38] F. Huang, H. Z. Zhang, J. F. Banfield, Nano Lett. 2003, 3, 373.

Received: August 25, 2011 Published online: February 16, 2012 